\title{
Assessment of Worries of Pregnant Women in Sokoto Northwestern Nigeria
}

\author{
Zuwaira Sani ${ }^{*}$, Oche Mansur Oche ${ }^{2}$, Ahmad Yakubu $^{3}$, Nwobodo Emmanuel ${ }^{3}$ \\ 'Department of Family Medicine, Usmanu Danfodiyo University Teaching Hospital Sokoto, Nigeria \\ ${ }^{2}$ Department of Community Health, Usmanu Danfodiyo University Teaching Hospital Sokoto, Nigeria \\ ${ }^{3}$ Department of Obstetrics \& Gynaecology, Usmanu Danfodiyo University Teaching Hospital Sokoto, Nigeria
}

Corresponding Author:

Dr Zuwaira Sani,

Department of Family Medicine, Usmanu

Danfodiyo University Teaching Hospital Sokoto,

Nigeria

E-mail: zuwairajimoh@gmail.com

Tel: 08033591835

\begin{abstract}
Background: Women experience multiple worries during the childbearing period, nearly every pregnant woman or her partner will worry about something pregnancy related at one point or another. The objectives of the study was to assess the worries of pregnant women using the Cambridge Worry Scale, compare the degree of worries between primigravida and multiparae pregnant women and compare worries of pregnant women by their stage of pregnancy.
\end{abstract}

Materials and method: The study was a cross-sectional descriptive study design. Four health centers were randomly selected and 361 pregnant women were recruited for the study. Data collection instrument was a selfadministered / interviewer-administered questionnaire developed using the Cambridge worry scale

Result and Conclusion: Ranking of worries of pregnant women using mean score value showed that pregnant women worry more about childbirth (1.99), their health (1.79), and possibility of something wrong with the baby (1.70) and money (1.40).

This study was able to assess the worries of pregnant women using the Cambridge Worry Scale. It is recommended that health care personnel should take more time in assessing pregnant women for the wellbeing of both the mother and baby.

Keywords: Worries, Pregnant Women, Sokoto, Northwestern Nigeria, CWS, Cambridge worry scale

\section{Introduction}

Pregnancy is a transition period in a woman's life characterized by physiologic and psychological changes (1). It is a period associated with heightened levels of emotion and anxiety $(2,3)$. It is usually associated with ambivalence, frequent mood changes varying from anxiety, fatigue, exhaustion, sleepiness and depressive reactions to excitement (4-6). Women experience multiple worries during the childbearing period, such as how pregnancy affects one's body image, whether the baby will be normal and healthy, how being pregnant affects the relationship with spouse or partner, whether to continue employment during or after pregnancy, and uncertainties about adequate finances to support the new or growing family (7-13). Fear and worry are so common for both partners in pregnancy that it has been suggested that it should be added to a list of pregnancy symptoms. Nearly every pregnant woman or her partner will worry about something pregnancy related at one point or another $(14,15)$.

It is in realization of the fact that pregnant women worry about the outcome of their pregnancy and wellness of their babies so much that it can have a detrimental effect on their health as well as psychosocial effect (16-18), coupled with the fact that no previous such study has been done in this part of world that this study is being 
undertaken. The data generated from this study can provide baseline data for future reference and intervention measures. These measures would be aimed at assisting women in their adaptation process, most importantly during pregnancy and postpartum. This work was therefore aimed at assessing the worries of pregnant women in Sokoto, Northwestern Nigeria, with specific objectives of assessing the worries using the Cambridge Worry Scale, comparing degree of worries between primigravida and multiparae and comparing worries of pregnant women by their stage of pregnancy.

\section{Material and Methods}

The study was a cross-sectional descriptive in design. The study population comprised of pregnant women attending antenatal clinics in Sokoto, Northwestern Nigeria.

The sample size was determined using the following formula;

$$
\mathrm{n}=\mathrm{Z}^{2} \mathrm{pq} / \mathrm{d}^{2}
$$

where

$\mathrm{n}=$ minimum required sample size where population is greater than 1000

$\mathrm{Z}=$ standard normal deviation at $95 \%$ confidence level, = 1.96

$\mathrm{P}=$ proportion of success or prevalence $=0.69$ for the standard deviation of all items of CWS in study conducted at Cambridge (4)

$\mathrm{q}=$ proportion of failure $1-0.69=0.306$

$\mathrm{d}=$ tolerable alpha error $=0.05$

$\mathrm{n}=(1.96)^{2} \times 0.69 \times 0.306 /(0.05)^{2}$

$\mathrm{n}=324.4$, approximately 325 subjects.

A response rate ' $\mathrm{R}$ ' of $90 \%$ is anticipated hence sample size to be selected is given by

$\mathrm{n}=\mathrm{n} / \mathrm{R}=325 / 0.9=361$.

Therefore 361 subjects were selected.

By simple random sampling, four health facilities were selected with one each from the four local government areas that makes up Sokoto metropolis ie, Sokoto North, Sokoto South and some parts of Wamakko and Dange Shuni. . Proportional allocation using systematic random sampling was made to each health facility by dividing the number of pregnant women attending antenatal clinic in each facility by overall daily antenatal clinic attendance for all health facilities multiplied by 361 . Data collection instrument was a self-administered / intervieweradministered questionnaire developed using the Cambridge worry scale (CWS) for assessing the content and extent of worries in pregnancy (4). It contains items concerning such issues as the baby's health, own health, money, housing and employment, relationship with partner, family and friends, giving birth and coping with the new baby. An open-ended question at the end of the questionnaire gives respondents the opportunity to report other concerns not included in the scale. Additionally, the questionnaire sought information on obstetric history and previous antenatal consultations. The questionnaire was sorted out for accuracy and completeness.

Statistical analysis

Data analysis was done using Microsoft Excel and Graph pad Istat. Descriptive statistics such as means, standard deviations and frequencies were used to present the demographic characteristics of the participants. Mean values and standard deviations were calculated for each item on the CWS, the total sum scores of the CWS of respondents and also major worries according to parity. Level of statistical significance was at $p \leqslant 0.05$. Differences between gestational groups were tested by one-way analysis of variance (ANOVA). Differences between primiparae and multiparae was determined using Chi Square test. Each item was scored on a sixpoint scale ranging from not a worry (0) to major worry (5).

\section{Results}

Socio-Demographic Characteristics of Respondents: A total of three hundred and sixty-one (361) pregnant women (Respondents) were studied, all of whom were married with the exception of one divorcee. The response rate was $100 \%$. The ages of respondents ranged from $15-$ 40 years, most of the respondents $222(61.5 \%)$ were within the age group of 20-29 years. The mean age of respondents was $25.5 \pm 5.3$ years (Table 1). Majority of respondents $254(70.4 \%$ ) were full-time housewives not gainfully employed and $67(18.6 \%)$ were traders. Only $32(8.9 \%)$ were civil servants and 5(1.4\%) were students (Table 1). A significant proportion of respondents 284(78.7\%) were Hausa by tribe while Yoruba and Igbo accounted for $26(7.2 \%)$ and $25(6.9 \%)$ respectively (Table 1). A total of 207 respondents accounting for over $57 \%$ of the sample size had some form of western 
education while $154(42.7 \%)$ had no form of western education (Table 1). Three-quarter (75\%) of respondents were multiparous women while remaining $(25 \%)$ were primipara. More than half $214(59.3 \%)$ of the respondents were within the gestational age 27-39 weeks while only $5(1.4 \%)$ were $\leqslant 13$ weeks (Table 1$)$.

Majority $321(88.9 \%)$ of respondents had some form of worry, with childbirth $95(26.3 \%)$, own health $76(21.0 \%)$, and the possibility of something wrong with the baby $64(17.7 \%)$ accounting for the top three major worries. Employment problems 14(3.90\%), coping with the baby $12(3.30 \%)$, and giving up work $6(1.70 \%)$ were the three lowest worries (Table 2).

Ranking of worries of pregnant women: Ranking of worries of pregnant women using mean score value showed that pregnant women worry more about childbirth (1.99), own health (1.79), possibility of something wrong with the baby (1.70), money (1.40), going to hospital (1.36), internal examinations (1.12), and miscarriage (1.12) as the top seven worries in descending order. Employment problem (0.37), giving up work (0.41), relationship with family and friend (0.82), Housing (0.84), relationship with spouse (0.90), coping with the baby (0.96), and health of someone close to you (1.00) as the bottom seven worries in ascending order (Figure 1).

Comparison of the respondents' worries by gravidity: Comparing worries with parity revealed that there is no significance difference between primigravida and multiparae.

Comparison of worry: Comparing the three most worried about items on the Cambridge worry scale reveals that there was no significant difference in worries in relation to gestational age (Table 3 ).

Additional worries of pregnant women: Enquiry about additional worries revealed that $48(13.3 \%)$ of the respondents had additional concerns of which, $24(50 \%)$ of them were worried about the attitude of maternity care providers, and $14(29.2 \%)$ worried about their own health (Table 4)

\section{Discussion}

Majority of the respondents were full-time housewives, not gainfully employed. This could be explained by the fact that Northern Nigeria where this study was conducted and especially in Sokoto state, most men prefer to have their wives at home. The culture also frowns at women that are working class mothers believing that the place of women should be at home with the kids. In this study $57.3 \%$ were formally educated, this figure is greater than the report by Nigeria Demographic and Health Survey (19). This might be explained by the fact that, most of the educated pregnant women preferred to attend antenatal care in the Teaching Hospital where majority of the women in the study were recruited. Compared to study done by (20), $82 \%$ of participants were educated up to tertiary level which was higher than what was obtained in this study.

The topmost of the worries reported was about giving birth. This is similar to the study by (21). On the other hand, this is in contrast to the study by $(4,10,13)$ where worry about the health of the baby was the top most worry. The second major worry in this study was that of self-health. This differs from similar studies where worry about own health was low in the list $(4,10,11)$. The third major worry was the worry about possibility of something being wrong with the baby. This is contrary to report of similar studies where worry about baby's health was the topmost worry $(10,11,13)(14)$. The ranking was lower in this study because these women attended antenatal care and the worry about the baby's health is strongly influenced by antenatal care, and women have high expectations for antenatal care in terms of possibilities for preventing fetal morbidity (22).

Contrary to study by (10) that reported worry about internal examination as the ninth on the scale of major worries, it was the fourth in this work. This could be attributed to the religious and cultural beliefs prominent in the Muslim-dominated study area where most women are worried about exposing themselves before the health workers of opposite sex. Worry about the possibility of having a miscarriage accounts for only $17.1 \%$. The fact that this item was low on the scale of major worries was not surprising owing to the fact that pregnant women in the study area seldom book their pregnancy early. Most of the women seen in the hospital for antenatal care were usually in their second or third trimester making the worry of possibility of miscarriage to be diminished at these times because it is mostly related to first part of pregnancy (10). It is surprising that worry about money accounts only for $8.6 \%$ of major worries considering the economic situation in the developing world but from cultural and religious point of view, people from this part of the world are usually more reserved and this would make them less inclined to indicate their true financial 
situation.

\section{Conclusions and Recommendations}

This study has been able to assess the worries of pregnant women in Sokoto, Northwestern Nigeria, using the Cambridge Worry Scale. The main worries of these women being worry about giving birth, worry about their own health and worry about the possibility of something being wrong with the baby. The study also revealed that there was no significant difference in worries between primigravida and multiparae and there was also no significant difference when comparing worries in relation to gestational ages.

It is recommended that, health care providers take more time in assessing their pregnant clients and these women should be encouraged to voice out their fear and concerns so that their fear and worries can be alleviated to aid physical and mental wellbeing of the mother and the fetus.

\section{References}

1. Ciliberto CF, Marx GF. Physiological changes associated with pregnancy. Adv Anesth. 1998;9(2):1-3.

2. Affonso DD, Liu-Chiang C-Y, Mayberry LJ. Worry: conceptual dimensions and relevance to childbearing women. Health care for women international. 1999;20(3):227-36.

3. Bhagwanani $S G$, Seagraves K, Dierker LJ, Lax M. Relationship between prenatal anxiety and perinatal outcome in nulliparous women: a prospective study. Journal of the National Medical Association. 1997;89(2):93.

4. Green JM, Kafestios K, Statham H.E., Snowdon C.M.Factor Structure, Validity and Reliability of Cambridge Worry Scale in a preganant population. .Journal of Hlth Psychology.2003.;8(6): 7537640

5. Bjelica AL, Kapor-Stanulovi? P. Pregnancy as a psychological event. Medicinski pregled. 2004;57(3-4):144-8.

6. Breitkopf CR, Primeau LA, Levine RE, Olson GL, Wu ZH, Berenson AB. Anxiety symptoms during pregnancy and postpartum. Journal of Psychosomatic Obstetrics \& Gynecology. 2006;27(3):157-62.

7. Statham H, Green JM, Kafetsios K. Who worries that something might be wrong with the baby? A prospective study of 1072 pregnant women. Birth. 1997;24(4):223-33.

8. Jinadu MK, Daramola S. Emotional changes in pregnancy and early puerperium among the Yoruba women of Nigeria. International
Journal of Social Psychiatry. 1990;36(2):93-8.

9. Drake ML, Verhulst D, Fawcett J. Physical and psychological symptoms experienced by Canadian women and their husbands during pregnancy and the postpartum. Journal of advanced nursing. $1988 ; 13(4): 436-40$.

10. Öhman $S G$, Grunewald $C$, Waldenström U. Women's worries during pregnancy: testing the Cambridge Worry Scale on 200 Swedish women. Scandinavian Journal of Caring Sciences. 2003;17(2):14852.

11. PEÑACOBA? PUENTE C, MONGE FJC, MORALES D. Pregnancy worries: a longitudinal study of Spanish women. Acta obstetricia et gynecologica Scandinavica. 2011;90(9):1030-5.

12. Monge FJC, Peñacoba-Puente C, Morales DM, Abellán IC. Factor structure, validity and reliability of the Spanish version of the Cambridge Worry Scale. Midwifery. 2012;28(1):112-9.

13. Gourounti K, Lykeridou K, Taskou C, Kafetsios K, Sandall J. A survey of worries of pregnant women: Reliability and validity of the Greek version of the Cambridge Worry Scale. Midwifery. 2012;28(6):74653.

14. Glazer G. Anxiety levels and concerns among pregnant women. Research in nursing \& health. 1980;3(3):107-13.

15. Grant K-A, McMahon C, Austin M-P. Maternal anxiety during the transition to parenthood: a prospective study. Journal of affective disorders. 2008;108(1):101-11.

16. Borkovec $T, H u S$. The effect of worry on cardiovascular response to phobic imagery. Behaviour Research and Therapy. 1990;28(1):6973.

17. Leifer M. Psychological effects of motherhood: A study of first pregnancy: Praeger Publishers; 1980.

18. Jomeen J. The importance of assessing psychological status during pregnancy, childbirth and the postnatal period as a multidimensional construct: A literature review. Clinical Effectiveness in Nursing. 2004;8(3):143-55.

19. Rai RK, Singh PK, Singh L. Utilization of maternal health care services among married adolescent women: insights from the Nigeria Demographic and Health Survey, 2008. Women's Health Issues. 2012;22(4):e407-e14.

20. Adewunmi A, Rabiu K, Tayo A. Gestational age at antenatal booking in Lagos, South-West Nigeria. Internet J Gynecology and Obstetrics. 2009;12(1).

21. Petersen JJ, Paulitsch MA, Guethlin C, Gensichen J, Jahn A. A survey on worries of pregnant women-testing the German version of the Cambridge Worry Scale. BMC Public Health. 2009;9(1):490.

22. Hildingsson I, Waldenström U, Rådestad I. Women's expectations on antenatal care as assessed in early pregnancy: number of visits, continuity of caregiver and general content. Acta obstetricia et gynecologica Scandinavica. 2002;81(2):118-25. 